\title{
Strengthening factory health systems under Levi Strauss \& Co.'s worker well-being initiative in Egypt
}

Population Council

The Evidence Project

Follow this and additional works at: https://knowledgecommons.popcouncil.org/departments_sbsr-rh

Part of the Demography, Population, and Ecology Commons, Family, Life Course, and Society Commons, and the International Public Health Commons How does access to this work benefit you? Let us know!

\section{Recommended Citation}

"Strengthening factory health systems under Levi Strauss \& Co.'s worker well-being initiative in Egypt." Washington, DC: Population Council, Evidence Project, 2016. 


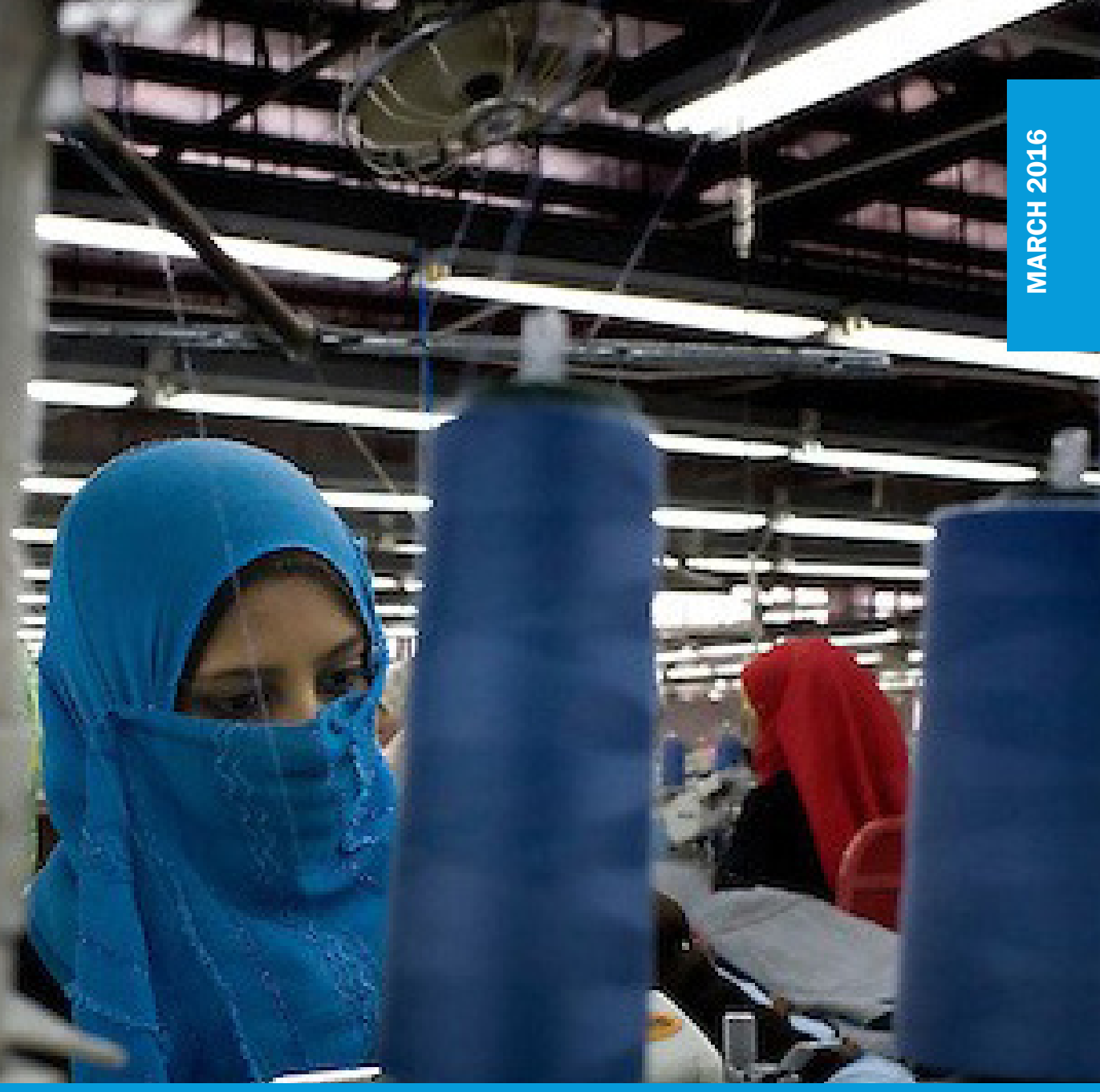

BRIEF

\section{STRENGTHENING FACTORY}

\section{HEALTH SYSTEMS UNDER LEVI}

STRAUSS \& CO.'S WORKER WELLBEING INITIATIVE IN EGYPT

The pilot intervention described in this brief took place at an apparel manufacturing company, Lotus, located in Port Said, Egypt as part of the Worker Well-being Initiative. Worker Well-being is an initiative of Levi Strauss \& Co. (LS\&Co.) and the Levi Strauss Foundation (LSF) that seeks to move beyond a "do no harm" compliance model of labor rights in its global supply chain. This brief highlights a promising model for strengthening a factory's management of workplace infirmaries and health activities and improving health services and education for workers.

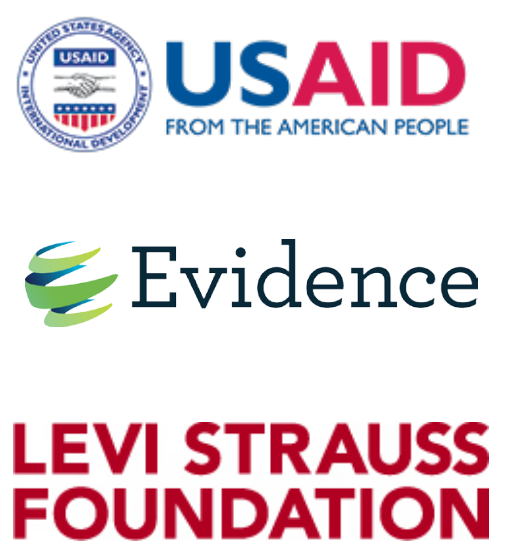




\section{BACKGROUND}

Increasingly, women have become a driving force in our global economy. Even though the makeup of the workforce has changed, women's health remains is a low priority for most multi-national corporations and their supply chain suppliers in low- and middleincome countries. Health at the workplace is viewed through the narrow, traditional lens of occupational health and safety (OHS) compliance. In this context, companies focus on inputs (number of nurses or availability of first aid kits) and safety issues (use of protective clothing) rather than on the provision of quality health services, including access to safe, voluntary FP and RH counseling and services, for their employees. Health staff are seen as a cost, not a strategic resource. As a result, the quality and management of health services provided are under-prioritized, and workplace health providers who could do much more to promote healthier behaviors are underutilized.

Worker Well-being is an initiative of Levi Strauss \& Co. (LS\&Co.) and the Levi Strauss Foundation (LSF) that seeks to move beyond a "do no harm" compliance model of labor rights in its global supply chain. Worker Well-being involves collaborating with suppliers to improve the lives of apparel workers in three domains: (1) economic empowerment, (2) good health and family well-being, and (3) equity and acceptance. It takes a continuous improvement approach that emphasizes ownership of activities by factories and recognizes that employee needs and factory capacity will vary by location. Pilot projects took place in partnership with leading suppliers in five of the Company's priority countries: Bangladesh, Cambodia, Egypt, Haiti and Pakistan to inform the Worker Well-being approach.

The pilot intervention described in this brief took place at an apparel manufacturing company, Lotus, located in Port Said, Egypt. The factory has a commitment to the health of its workers and is a strategic supplier to LS\&Co., which contributed to its inclusion in LS\&Co.'s Worker Well-being initiative. At the start of this project in 2013, the factory employed just under 6,500 workers with 2,753 of them women, more than half who were married. The factory had six clinical sites in each production hall staffed by six nurses. Today, the company is the largest Egyptian garment exporter suppling brand names such as Levi Strauss and Co. (LS\&Co.), Calvin Klein, and Jones Apparel Group and employs over 11,000 workers. With the factory expansion, this grew to 12 clinics and 12 nurses (one male nurse).

The results of the Egypt pilot contributed to the further development of the Worker Well-being approach, which LS\&Co. is rolling out to its global network of strategic suppliers. LS\&Co.'s new model for supply chain engagement is designed to integrate Worker Well-being programs into its suppliers' ongoing business operations for long-term sustainability.

TABLE 1: ROLES AND RESPONSIBILITIES OF PROJECT PARTNERS

\section{ORGANIZATION}

Business for Social
Responsibility
(HERproject)

Egyptian Family Planning Association (EFPA)

The Evidence Project/ RAISE Healthier

\section{ROLE}

Project Management

Local Implementation Partner

Technical Assistance Provider

\section{RESPONSIBILITIES}

BSR's HERproject team provided the overall management for all components of the Egypt Worker Well-being intervention. HERproject is a 12-month health education and awareness raising program to improve the health knowledge and behaviors of women and men workers as well as workplace nurses. The curriculum includes reproductive health, family planning, nutrition, general and menstrual hygiene and sexually transmitted diseases.

EFPA, an affiliate of the International Planned Parenthood Federation, worked closely with BSR in the planning, implementation, and evaluation of HERproject at Lotus on the ground. Its staff trained the peer educators and nurses and managed the relationship between Lotus management and the implementation team.

The Evidence Project through its partner for the RAISE Health activities, Meridian Group International, Inc., provided BSR and EFPA long-distance technical assistance on its model for establishing health standards and management systems in factories and improving and expanding the clinical health services for men and women workers. 


\section{APPROACH}

In Egypt, the main focus of Worker Well-being (WWB) is health, including reproductive health. The health interventions were managed by Business for Social Responsibility's (BSR) HERproject and implemented by its local partner, the Egyptian Family Planning Association (EPFA). The Evidence Project/RAISE Health's role was to help integrate a model for strengthening factory health systems as a component of the intervention that would address the quality of the clinical services and practices of the health staff and infirmaries and support the HERproject program of worker health education activities using a peer education approach.

The role of the Evidence Project/RAISE Health was to provide technical assistance in incorporating a model for strengthening the factory's health functions by:

1. Expanding the role of nurses;

2. Developing clinical quality standards and practices; and

3. Integrating management systems and oversight of health functions.

This approach responds to common weaknesses of infirmaries and health services at workplaces globally: nurses are under-utilized resources; factory management provides minimal oversight of health functions; and infirmaries often to do not follow basic clinical practices on confidentiality, hygiene and client-centered services. All three components are critical for a workplace to address sensitive women's - and men's - health issues, especially family planning. The Egypt factory provided a good setting for this activity as the factory ownership was committed to worker health and had in place infirmaries staffed with nurses.

Through this approach, the goal was to improve services and health outreach to men and women workers, a large part of which addressed reproductive health and family planning. An equally important goal was to strengthen the factory capacity and systems in ways that would sustain new clinical practices as well as HERproject-type health education in the factory.

Security concerns in Egypt limited the Evidence Project/RAISE Health involvement to providing long-distance technical assistance to EFPA, which was responsible for onsite implementation of all project activities.

Our technical assistance included:

1. Providing tools for and guidance in the assessment of clinics' services and infirmary;

2. Supporting the analysis of the assessment and the development of a management action plan;

3. Identifying systems already in place at Lotus that could better support health care delivery and overall operations at the factory, and enhance these systems;

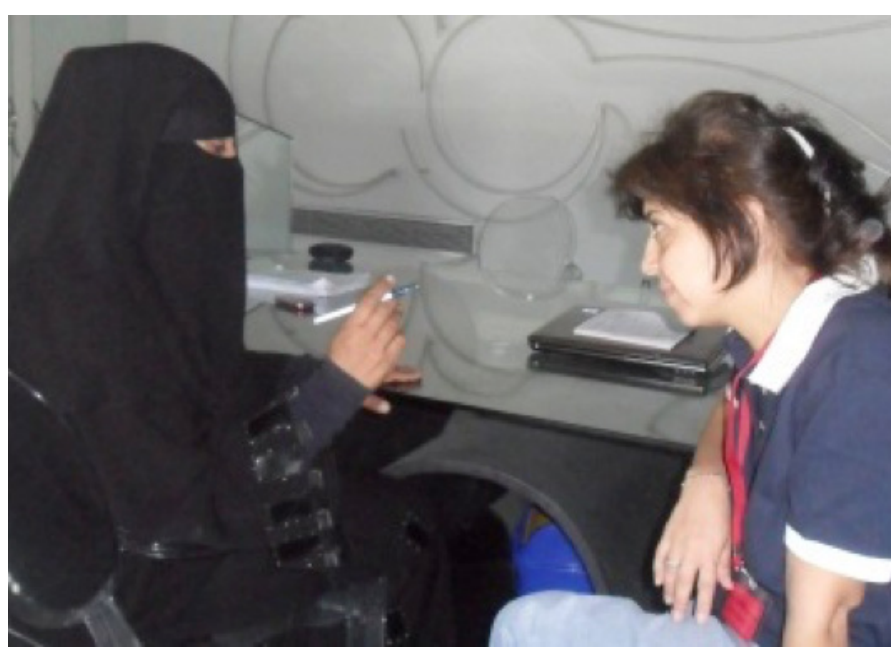

4. Providing documents such as management tools, clinical job aids and project evaluation as well as management training materials and lessons learned from our work in other factories around the world; and

5. Supporting ongoing activities of BSR and EFPA to address implementation issues and challenges as they occurred over the project term.

\section{INTERVENTION}

The HERproject interventions targeted about 6,500 factory workers, factory management, and nurses. The nurses provided health education on such topics as family planning and reproductive health, personal and menstrual hygiene, nutrition, sexually transmitted infections, pre- and post-natal care, and general health. EFPA trained 88 men and 108 women workers as peer educators to speak to their co-workers on those health topics. Although the Evidence Project/RAISE Health's role did not include technical assistance for the implementation of HERproject's peer health education program, it was directly linked to it as our work focused on the structures, systems and practices that are necessary to support health education activities over the long term.

The Evidence Project/RAISE Health strengthened factory health systems and practices by addressing three inter-related components:

\section{Expanding the Role of the Nurses}

Factory nurses are capable of providing far more services to workers than they are formally expected to do - which mainly involves curative healthcare for injuries and work-related ailments. These nurses can offer preventive health care and education and promote access to services on important issues like reproductive health, family planning, and maternal and child care. The Evidence Project/RAISE Health helped BSR and EFPA to secure management agreement to allow a more active role for the nurses and assume formal responsibility for: 
- Overseeing the weekly activities of the peer health educators (PHEs);

- Managing the overall factory health education program, including being trained as Master Trainers on health; and

- Providing private, one-on-one, health education or counseling sessions on sensitive topics like reproductive health to workers, which were termed "personal awareness sessions".

Based on the clinical assessment in which certain nurses lacked interest in taking on increased management responsibility of the PHEs, EFPA selected the four most capable and engaged nurses, rather than all factory nurses, to assume an expanded role. These four nurses received further training on health topics and in interpersonal communication and facilitation skills necessary to become Master Trainers for peer educators. This training was designed to build the factories internal capacity to maintain the peer education program as it would be embedded in the nurses' job responsibilities, which now included providing refresher trainings to current PHEs and new PHE trainings to workers needed to replace those PHEs who leave the program through natural turnover. Each nurse was then assigned to manage 33 PHEs in a production hall. EFPA also built the capacity of the nurses to develop a health education plan each month, with topics, a timeline and the number of sessions to be implemented by nurses and peer educators.

Additional training in health topics such as reproductive health and family planning enabled the nurses to offer personal awareness sessions to individual workers who wanted to discuss more sensitive health topics with a health provider. These personal awareness sessions covered topics such as family planning for the newly married, STIs, breast and cervical cancer screening, menstrual hygiene, and female genital mutilation. In order to increase the utilization of the one-on-one counseling sessions, notices

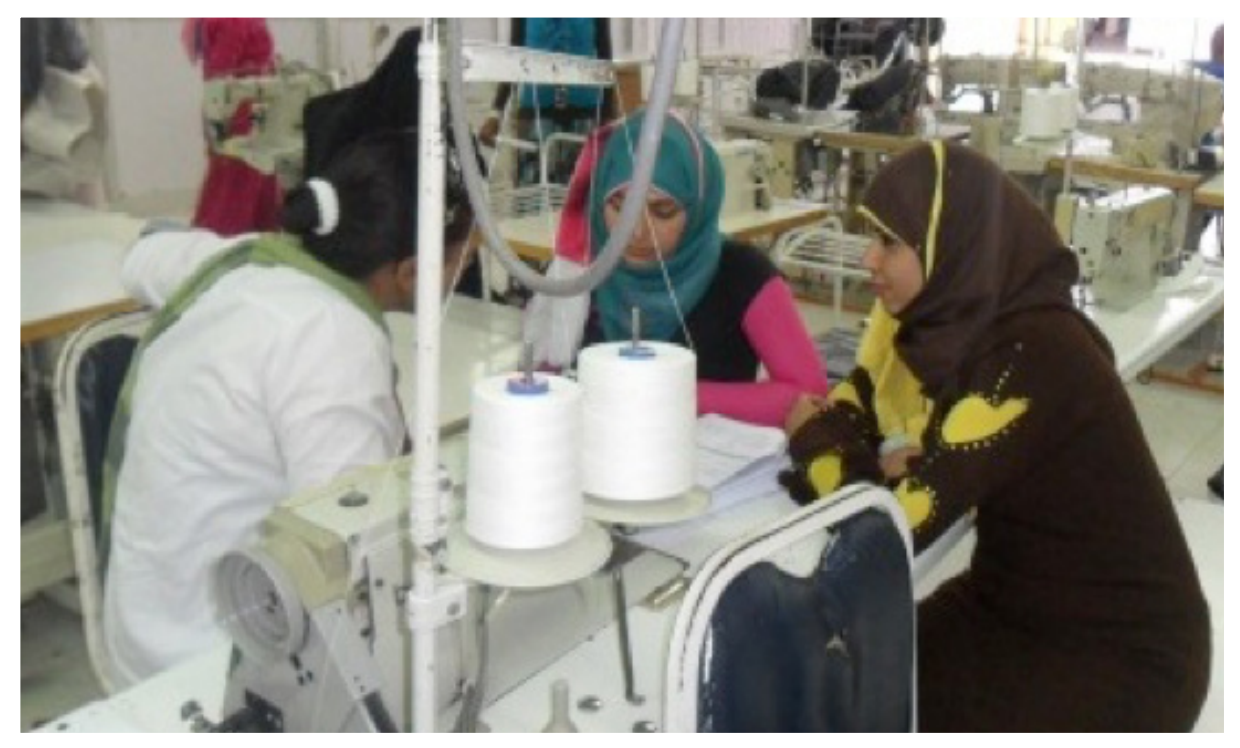

were posted in the clinics and production halls. A flip chart was also produced on family planning methods to serve as a job aid for the nurses.

\section{Developing Clinical Quality Standards and Practices}

RAISE Health provided technical assistant to EFPA to undertake an assessment of the factory's infirmary and clinical practices. The focus of the assessment was to ensure that the factory clinics met basic patient care standards for confidentiality and hygiene - essential changes if women workers are to see the factory clinic and staff as a safe place to discuss sensitive reproductive health issues. The assessment was done by a consultant to EPFA who was a board-certified doctor and medical professor using an assessment tool adapted by the Evidence Project/RAISE Health to review the physical state of the clinics, the infirmary products and services, and staff practices.

The assessment identified several gaps relating to patient confidentiality and privacy. The infirmary door was often left open when the nurse or doctor saw patients, and the waiting area location enabled people to hear confidential conversations. Infection control, such as hand washing and disposal of sharps called for improved practices. There was also a need for health information to be posted in the clinics and other areas in the factory.

EFPA worked with the factory to develop written procedures for quality and patient safety and hygiene practice. Nurses were then trained on these standards and job aides were posted in the clinics. Clinic doors were routinely shut when meeting with patients. Health education posters on hand hygiene were posted in washrooms and common areas in the factory. Brochures on handwashing were also provided as handouts for workers to take home. These materials complemented other educational materials provided by HERproject.

The assessment also highlighted non-clinical issues such as lack of communication between management and the nurses on the peer health education activity and the lack of interaction between the nurses and the peer educators.

\section{Integrating Management and Clinical Functions}

The greatest challenge for management in workplaces is to recognize the importance of a more active supervisory role of their health functions and staff. Long-term management engagement with and oversight of the health team is important not only to en- 
sure the new role of nurses and clinical standards are sustained, but also to establish a commitment to continuous improvement. Human resource and other managers in factories tend to view health as a technical area that they cannot manage. They leave it to health professionals to supervise themselves. As workplaces have no clinical manager position as might be found in a public health clinic, workplace infirmary staff are assumed to be applying good clinical practices on their own. Formalizing an oversight structure is necessary to improving the company's health services over time. At the Egypt factory, there was a part-time doctor that provided some clinical oversight, but did not have the time for overall management of clinical practices and procedures. The Evidence Project/RAISE Health worked with HERproject and EFPA to increase management oversight in three areas:

- Human resources tools

- Data collection and use

- Management systems

The first step in increasing management oversight of health functions and coordination of health activities was to revise two human resource tools: (1) nurse job descriptions and (2) nurse performance checklist. As the original job descriptions emphasize occupational health functions, this exercise helped clarify their other roles and responsibilities, particularly relating to health education and outreach.

\section{"I started working in the factory 15 years} ago, my relationship with the men and women workers was always good. However, the project made the relationship between us closer and I gained their trust more. I feel now that I am the first person they ask if they need any health-related information or help with personal issues as well."

- Nurse

Second, the team focused on the collection and aggregation of clinical data on service delivery. The goal was to enable the health staff and factory management to use this information to respond to the health needs of workers and inform the health education program. EFPA collaborated with the nurses to revise the clinical data collection tool to enable analysis by gender and disease category. The Evidence Project/RAISE Health also provided EFPA with a guidance document that could be used to train the team on data analysis, presentation, and action.
Finally, the Evidence Project/RAISE Health and EFPA focused on ensuring management systems led to increased interaction between management and the nurses. This included establishing a Health Management Team consisting of the doctor, four nurses, the Human Resources Manager and a senior manager. This group was to follow a regular meeting schedule to discuss issues pertaining to worker health, health education activities and the health outreach program. The factory also linked the health function to existing processes. For instance, a nurse would serve on the Health and Safety Committee to present health and education information to the group. As part of the factory's process for soliciting worker feedback, suggestion boxes for improving health services were strategically placed, and advertised in the production halls. A plan was developed to discuss any suggestions made at the Health and Safety committee meetings. A training was also provided to factory line supervisors of the business value of health activities.

\section{RESULTS}

The findings described below focus only on the activities supported by the Evidence Project/RAISE Health. These are informed by a report by BSR/EFPA on overall HERproject interventions at the factory. ${ }^{1}$ The factory health system strengthening model showed its strongest results in the areas of changing the roles of the nurses and improving clinical practices. The management systems integration remained a work in progress, as will be discussed below.

\section{Nurse Role}

The BSR/EFPA report also suggests that the project succeeded in changing the role of the nurse as a source of information and as a supervisor of the peer health educators as well as in making the clinic a trusted place for one-on-one private discussions between women workers and the nurses. Of the 97 women surveyed, 91 percent reported having used the factory clinic in the previous six months for sexual and reproductive health information and services, which were introduced through this pilot project. Nurses told EFPA that these visits were mainly to address pain related to menstruation, but also to discuss family planning and child health. In focus groups, the BSR/EFPA report says, "The workers shared that they were comfortable speaking with the nurses and asking the nurses questions without fear. They also mentioned that they now feel that the clinic is a very safe place, and they have started to speak about their needs and ask their questions with more ease than before." Each of the four trained nurses stated that they received several requests from workers for private counseling, and that the demand has increased during the course of the program. They estimated they each held about 15-20 sessions a month.

The PHEs reported that they see their nurse supervisor daily, and 
regularly seek her guidance on women's health and occupational health issues. The lead nurses completed an education plan for 2015, and each month they met to coordinate the session topics and educational materials needed. Each nurse does four training or health information sessions a month for the PHEs she supervises. In the summer of 2015, the nurses included workers with the PHEs in the information sessions. The first sessions focused on family planning and child health. At the end of the pilot, EFPA observations of the four trained nurses were that three of the four were fully engaged in and comfortable with their new role managing the PHEs and overseeing health education and training. One nurse became "passionate" about the work, putting posters on the clinic wall and collecting and disaggregating clinic data.

\section{Clinic Standards \& Practices}

In a follow-up rapid assessment, EFPA found that overall the level of cleanliness and organization of the clinics had improved and new procedures appeared to be in place. All the clinics were provided with Sterilium, soap, and Dettol. Moreover, the proper disposal containers for medical waste and sharp needles were now available in the clinics, which also presented wall posters on hand hygiene. The factory also signed a Memorandum of Understanding with a local hospital for waste collection based on country guidelines. In fall 2014, EFPA produced a list of procedures based on World Health Organization and Egyptian Ministry of Health and Population (MoHP) guidelines for the clinics. Each clinic had a printed copy of quality and safety procedures, and the 11 nurses were formally oriented on those procedures. Flipcharts, brochures, and manuals produced by HERproject were visible in all the clinics. Finally, the health staff made some improvements in the data collected in the clinic registers, but this work was not supported by oversight from management.

\section{Management Integration}

The Egypt factory made the least progress on this component, not surprisingly as it represents a significant change in perspective and practice by management. There were minor changes. For instance, the nurse job descriptions were updated to reflect the expanded role, however a performance checklist was not created even though the concept was approved by the doctor and management. A nurse was selected to serve for the first time on the factory Health and Safety Committee, but this committee did not end up meeting during the project period.

The broader changes related to a formal process for interaction between the health staff and management did not take hold during the project period (February 2014 - April 2015). A health team consisting of the doctor, four nurses and at least one representative of management was to have met monthly, but only met twice. The human resources staff was to work with the nurse to disaggregate the clinic data by sex and health issue and begin to identify health trends during the year. This work did not happen due to personnel issues and changes to the factory's managerial structure.

\section{LESSONS LEARNED}

Support from senior leadership is always an essential component of any successful workplace project. Lotus provided such support and put a senior manager in charge of the interventions who was also a champion of the work. However, the senior manager at the factory overseeing the entire project fell ill and was absent during much of the intervention period. This situation created uncertainty and a leadership void. While the middle management staff continued to be supportive of ongoing HERproject interventions, new activities related to more engaged health management did not become established without his leadership.

Senior leadership was particularly important as direct management of health functions by human resources staff was a new concept. EFPA was able to convince Lotus to establish monthly Health Management Team meeting of nurses and management after initial resistance. But, with the leadership void, these meetings were not established. Without regular, action-oriented meetings to discuss health practices, challenges, health trends and plans, there lacked the support structure and accountability to ensure all elements of the action plan were made and new priorities determined.

The civil instability and related security concerns for travel to Egypt made overall implementation more challenging. One important effect of this situation was that staff from the Evidence Project/RAISE Health (and BSR) could not provide onsite technical assistance either to EFPA or the factory management. It was possible to achieve results for this activity because of the Lotus' operational stability, the strong staff EFPA had on the ground and BSR's management role. Yet, certain components of the factory system-strengthening model were harder to support through long-distance communications.

An important lesson was that the management orientation and training on the business benefits of the HERproject interventions should have taken place earlier in the project, preferably at the start. This might have happened if there had not been travel limitations. The Evidence Project/RAISE Health would have been able to provide EFPA technical support in helping management to understand more fully the value of more engaged management oversight of health activities. The health orientation with line supervisors at the end of the project appeared to have been well received. EFPA, with technical assistance from the Evidence Project/RAISE Health, held two trainings on the business case for health with the factory's line supervisors that emphasized their role in sustaining the health program. EFPA reported that it felt 
the supervisor training was very important in gaining greater buyin for health activities. When asked for ideas about how to improve workers health, one of the supervisor group's suggestion was hiring a gynecologist at the factory or entering a formal contract with a private hospital to provide these services.

Overall, the Lotus leadership appeared to be very supportive and proud - of their efforts to improve the lives of their workers and views health as important. The BSR/EFPA report indicated that workers felt that line supervisors generally supported their attendance at the health trainings, a sign that senior management support for the health program had reached the frontline supervisors.

\section{RECOMMENDATIONS}

The Egypt factory is well-positioned to build on the structures and activities that have been established. They have an opportunity to make better use of existing health resources and sustain a proactive program of health services and education. One of the biggest challenges of implementing health programs in a factory setting is to create ownership of the activities by management. Ownership does not mean basic support and approval by leadership for others to do program implementation, but the establishment of the structures and systems within the factory to sustain the programs. Under LS\&Co.'s Worker Well-being initiative, the factory has made the commitments that are necessary to make a shift to 'structural ownership.'

The following recommendations emerged from this work:

\section{Build Human Resource Capacity}

The creation of a management structure in which the nurses have a clear role in supervising the PHEs and in training them was an important first step in institutionalizing health programming. The improvements to clinical practices, including for confidentiality and privacy, and the new "personal awareness sessions," provided women workers a safe place to discuss sensitive issues like reproductive health and family planning.

These accomplishments may not last if and when "trained" nurses leave the factory without a more robust management structure in place to ensure health practices operate regardless of personnel challenges and that new nurses are trained. As EFPA noted in their report, the current doctor is too busy to be able to handle the broader management needs of the health program. Even with the additional doctors the factory hired, management engagement and supervision will still be needed as the doctors are likely to be busy providing immediate services to the 11,000 workers.

Thus, a top recommendation is for the factory to continue building its human resources capacity to manage its overall health func- tions. A regular process for Health Team meetings is only the first step. Robust human resources or management support could include:

- A formal hiring process for nurses that identifies qualified candidates, trained in the health needs of workers and capable of health education and training;

- Use of health data to identify and act on health trends;

- Development of annual plans for health education and services; and

- A nurse performance checklist and process that reinforces quality practices and recognized good performance.

Data collection and analysis - and action - is an area where a robust management engagement can make a difference and help improve health activities. For example, the nurse who became passionate about data collection ideally would be supported and recognized as a resource and leader. In the future, Lotus factory might assign her responsibility and specific authority to build the capacity of other nurses to collect and analyze data and then use the data to determine health education topics as well as inform management of emerging worker health needs. She might also be assigned to work with a human resources officer to input data into spread sheets that allow deeper analysis and wider use. This opportunity for professional development of a talented nurse that benefits the company at little cost is a missed opportunity because management oversight structures for health remain limited. Data analysis is one area that could enable the factory in the future to use the information to improve and direct their health services and education.

\section{"It is very important for the workers to take care of their own health as this can directly affect the quality and the productivity of the work."}

-Management Member

\section{Ensure access to health services}

Related to this recommendation is the need to ensure women and men - workers have access to services they need. Personal awareness sessions and other counseling services with nurses or PHEs on issues like reproductive health and family planning are opportunities to help workers receive health services either onsite or offsite through referral. The large number of women using the clinic for reproductive health issues indicates an unmet need for these services. The existing factory relationship with EFPA offers 
an opportunity to provide these services nearby by establishing a formalized relationship and referral system.

\section{Commit to Continuous Improvement}

While the health "pilot" finished in April 2015 (with some ongoing support to the nurses through December 2015 by EFPA), the factory's commitment to the health program with LS\&Co. and Worker Well-Being is continuing. Since the initial implementation, the factory has nearly doubled in size, and scaling up health activities could reach well beyond the current beneficiaries. By building on its current investment to make systemic changes, Lotus can have a much greater impact on the health of all its workers. The systemic changes as well as changes to practices can take place only through a commitment to continuous improvement, and this will only happen if management resources and factory structures are there to support them.

\section{CONCLUSIONS}

The interventions in Egypt have contributed to the overall development of a health system strengthening approach to private workplaces, which is a new concept for management. It provided evidence that training nurses to manage workplace peer education programs and serve as master trainers, is a way to improve sustainability of workplace health education programs as they become embedded in the work of existing health professionals. The strengthened capacity of the nurses as well as improved management supervision and leadership on health should be part of any approach seeking to create shared value for companies, workers and communities. Having such structures and capable staff in place will enable management to make better use of existing resources and improve quality as well as seize opportunities to get more business and health value from any health activities they launch.

The work in Egypt also contributed to a collaboration between the Evidence Project/RAISE Health and BSR HERproject to develop Workplace Health Facility Guidelines for company management. The guidelines are designed to provide a practical road map for management to improve their workplace health functions and supervise the health staff. Furthermore, LS\&Co. intends to share the learning and guidance based on this health system strengthening model with its global supplier network to support their activities under the Worker Well-being initiative.

\section{REFERENCES}

1 HERhealth Final Report: Lotus Factory, Port Said, Egypt. Internal Report. Prepared for Levi Strauss \& Company by Business for Social Responsibly and Egyptian Family Planning Association. June 2015

\section{THE EVIDENCE PROJECT \\ Population Council \\ 4301 Connecticut Avenue NW \\ Suite 280 \\ Washington, DC 20008 USA \\ tel +12022379400 \\ evidenceproject@popcouncil.org}

CONTRIBUTORS

Carolyn Rodehau

The Evidence Project

David Wofford

The Evidence Project

Kim Almeida

Levis Strauss Foundation

Elissa Goldenberg

Business for Social Responsibility

\section{USAID}

The Evidence Project is made possible by the generous support of the American people through the United States Agency for International Development (USAID) under the terms of cooperative agreement no. AID-OAA-A-13-00087. The contents of this document are the sole responsibility of the Evidence Project and Population Council and do not necessarily reflect the views of USAID or the United States Government.

\section{Evidence}

The Evidence Project uses implementation science-the strategic generation translation, and use of evidence-to strengthen and scale up family planning and reproductive health programs to reduce unintended pregnancies worldwide. The Evidence Project is led by the Population Council in partnership with INDEPTH Network, International Planned Parenthood Federation, Management Sciences for Health, PATH, Population Reference Bureau, and a University Research Network

\section{LEVI STRAUSS FOUNDATION}

The Levi Strauss Foundation advances the human rights and well-being of underserved people touched by our business.

\begin{abstract}
Meridinn Group International, Inc.
Meridian Group International, Inc. is a woman-owned, small business that works with the private and public sectors to create innovative programs and partnerships that benefit both business and society. RAISE Health is a major activity of the USAID-funded Evidence Project. Implemented by Meridian Group International, Inc., an Evidence Project partner, RAISE Health combines implementation science with its extensive experience implementing workplace health programs and promoting better policies and practices within the global framework of codes and compliance.
\end{abstract}

(C) 2016 The Population Council, Inc.

Suggested Citation: “Strengthening Factory Health Systems under Levi Strauss \& Co.'s Worker Well-being Initiative in Egypt.” Brief. Washington, DC: Population Council, Evidence Project.

Photo credit on cover page: Scott Nelson 2008. Egyptian workers operate a production line for blue jeans at the Velocity Apparelz CO factory October 27, 2008 in Ismailia ,130 kilometers north of Cairo, Egypt. The Indian owned jeans company has been open in Egypt since 2001, employing 2700 Egyptian workers while supplying jeans to major companies that include Levi Strauss \& Co., Gap, Target, and Zara. 